\title{
Dieulafoy lezyonunda endoskopik tedavi
}

\author{
Endoscopic treatment of Dieulafoy's lesion
}

\begin{abstract}
Muhammet Yener AKPINAR, Erkin ÖZTAŞ, Derya ARAS, İsmail Hakkı KALKAN, Meral AKDOĞAN, Sabite KAÇAR, Yasemin ÖZDERIN ÖZiN, Zeki Mesut Yalın KILIÇ, Bülent ÖDEMiş, Selçuk DişiBEYAZ, Ertuğrul KAYAÇETiN
\end{abstract}

Türkiye Yüksek İhtisas Eğitim ve Araştırma Hastanesi, Gastroenteroloji Kliniği, Ankara

\begin{abstract}
Giriş ve Amaç: Çalışmamızda kliniğimizde Dieulafoy Lezyonu tanısı konulan hastaları, yapılan endoskopik tedavileri ve bu tedavilerin başarı oranlarını ortaya koymayı hedefledik. Gereç ve Yöntem: Kliniğimizde 2008-2016 tarihleri arasında endoskopileri yapılan hastalar 'Dieulafoy Lezyonu' tanısı için retrospektif olarak tarandı. Endoskopik tanısı Dieulafoy lezyonu olan hastaların servis yatışları, laboratuvar değerleri, kaç gün yattıkları, hastalıklarının nihai sonucu tespit edildi. Bulgular: 18 hasta çalışmaya alındı. En sık başvuru şikayeti melenaydı. Hastaların yedi tanesinde mortalite gerçekleşti. Klips, tek başına veya kombine olmak üzere en sık başvurulan endoskopik tedavi yöntemiydi. Klipsin tek başına uygulandığı hastalarla, klipsle beraber veya klips olmadan kombine tedavi uygulanan hastalar arasında mortalite açısından fark yoktu $(p=0,9)$. Adrenalinle beraber heater yapılan olgular dışlanarak yapılan subgrup analizinde klips uygulanan hastalarla klipsle beraber diğer yöntemlerin yapıldığı hastalar arasında mortalite karşılaştııılı. iki grup arasında yine mortalite açısından bir fark yoktu $(p=0,6)$. Sonuç: Çalışmamız klips tedavisine eklenecek adrenalin ve/veya heater koagülasyon gibi yöntemlerle yapılan kombine tedavinin mortaliteyi azaltmada klips monoterapisine kıyasla herhangi bir üstünlüklerinin olmadığını göstermiştir.
\end{abstract}

Anahtar kelimeler: Dieulafoy lezyonu, endoskopik tedavi, gastrointestinal sistem kanaması

\section{GíRIŞ}

Üst gastrointestinal sistem kanamaları sık görülen bir gastroenteroloji acilidir (1). Bu kanamalar endoskopik tedavi metodlarındaki ilerlemelere karşın halen daha önemli bir morbidite ve mortalite nedenidirler. Gastrointestinal sistem kanamalarının en sık nedeni peptik ülser ve erozyonlardır. Diğer nedenler arasında özofajit, varis kanamaları, Mallory-Weis lezyonları ve üst gastrointestinal sistem maligniteleri sayılabilir. Üst gastrointestinal sistem kanaması ile gelen hastalarda Dieulafoy lezyonunun (DL) rastlanma sıklığı ise \%1-2'dir (2). Bu lezyonlar nadir olmakla beraber sıklıkla masif kanarlar ve ilk endoskopide görülemeyebilirler. Nadir görülmeleri endoskopist için bu lezyonların tanısını koymayı ve tedavisini yönetmeyi zorlaştırmaktadır. Biz bu çalışmamızda kliniğimizde DL ta-

\footnotetext{
Iletişim: Muhammet Yener AKPINAR

Türkiye Yüksek Ihtisas Eğitim ve Araştırma Hastanesi, Gastroenteroloji Kliniği Kızlay Caddesi 06100, Sinhiye, Ankara

Tel: +90 $3123061000 \cdot E-m a i l:$ muhammet.yener@gmail.com
}

Background and Aims: This study describes the demographic features of patients with Dieulafoy's lesion, their endoscopic findings, endoscopic treatments, and their response to therapy. Materials and Methods: Endoscopy reports were screened for Dieulafoy's lesion between 2008 and 2016. Patients with this diagnosis were also screened to determine initial laboratory findings, endoscopic treatments, and response to therapy. Results: A total of 18 patients were diagnosed with Dieulafoy's lesion. The most frequent presentation was melena. Seven patients died during the follow-up period. Clip was the most frequent endoscopic treatment method either alone or in combination with other endoscopic modalities. There was no difference in mortality between patients who were treated with clip alone and those treated with the combined modality $(p=0.9)$. When patients treated with adrenalin and heater were excluded, no difference in mortality was observed between the clip group and the clip combined with other endoscopic treatment group ( $p=0.6$ ). Conclusion: This study demonstrated that additional endoscopic methods such as adrenalin and/or heater did not reduce mortality compared with clip monotherapy.

Key words: Dieulafoy's lesion, endoscopic treatment, gastrointestinal system bleeding

nısı konulan hastaları, yapılan endoskopik tedavileri, endoskopik tedavilerin başarı oranlarını ve hastaların takip periyodlarındaki surveylerini ortaya koymayı hedefledik.

\section{GEREÇ ve YÖNTEM}

Türkiye Yüksek İhtisas Hastanesi Gastroenteroloji Kliniği Endoskopi Ünitesi'nde 2008-2016 tarihleri arasında endoskopileri yapılan hastalar 'Dieulafoy Lezyonu' tanısı için retrospektif olarak tarandı. Endoskopik tanısı DL olan hastaların servis yatışları, laboratuvar değerleri, kaç gün yattıkları, hastalıklarının nihai sonucu hasta dosyalarından ve hasta verilerinin tutulduğu bilgisayar programından derlendi. 
İstatistiksel analiz IBM 21.0 software programı ile yapıldı. Kolmogrov-Smirnov testi değişkenlerin dağılımını incelemek için kullanıldı. Mann-Whitney U testi nonparametrik değişkenlerin karşılaştırılmasında kullanıldı. Fisher testi ve x2 testi iki kategori arasındaki ilişkiyi değerlendirmede kullanıldı. p<0,05 anlamlı olarak kabul edildi.

\section{BULGULAR}

Dieulafoy tanısı alan toplam 18 hasta çalışmaya alındı. Bu hastaların hepsine özofagogastroduodenoskopi ile tanı konulmuştu. Hastaların 11 tanesi erkek, 7 tanesi kadın olup yaş ortancaları 72,5 olarak bulundu. Kadın hastaların yaş ortancası 78 (61-88) iken erkek hastaların yaş ortancası 66 (23-88) olarak tespit edildi $(p=0,07)$. Hastalara minimum 1 ve maksimum 3 olmak üzere farklı sayılarda endoskopi yapılmıştı. Ortanca yatış günü 10,5'ti. Hastala-

Tablo 1. Hastaların demografik özellikleri ve başvuru esnasındaki laboratuvar değerleri

\begin{tabular}{|c|c|}
\hline Değişken & Ortanca Değer \\
\hline Yaş & $75,2(23-88)$ \\
\hline Erkek & $66(23-83)$ \\
\hline Kadın & $78(61-88)$ \\
\hline \multicolumn{2}{|l|}{ Cinsiyet } \\
\hline Erkek & $11(\% 61,1)$ \\
\hline Kadın & $7(\% 38,9)$ \\
\hline Yatış günü & $10,5(1-28)$ \\
\hline Endoskopi sayısı & $1(1-3)$ \\
\hline \multicolumn{2}{|l|}{ Başvuru şikayeti } \\
\hline Melena & $9(\% 50)$ \\
\hline Hematemez & $2(\% 11,1)$ \\
\hline Melena+Hematemez & $4(\% 22,2)$ \\
\hline Belirsiz & $3(\% 16,7)$ \\
\hline \multicolumn{2}{|l|}{ Mortalite } \\
\hline Mortalite var & $7(\% 38,9)$ \\
\hline Mortalite yok & $11(\% 61,1)$ \\
\hline \multicolumn{2}{|l|}{ Laboratuvar } \\
\hline Hemoglobin & $9,5(5,7-11,9)$ \\
\hline Lökosit & $7.900(5.100-19.000)$ \\
\hline Platelet & $144.000(91.000-342.000)$ \\
\hline INR & $1,14(1-2,5)$ \\
\hline ALT & $18(4-27)$ \\
\hline AST & $17(7-83)$ \\
\hline GGT & $23(11-63)$ \\
\hline ALP & $65(39-125)$ \\
\hline Total protein & $5,9(4,8-6,5)$ \\
\hline Albümin & $3,2(1,5-3,9)$ \\
\hline
\end{tabular}

INR: Uluslararası normalleştirilmiş oran, ALT: Alanin aminotransferaz, AST: Aspartat aminotranferaz, GGT: Gama glutamil transpeptidaz, ALP: Alkalen fosfataz rın en sık başvuru şikayeti melena olup bunu sırasıyla melenayla beraber hematemez ve sadece hematemez izledi. Takiplerde hastaların yedi tanesi mortal seyrederken, 11'i şifa ile taburcu edildi. Hastaların demografik ve laboratuvar verileri Tablo 1'de verilmektedir.

Endoskopide DL farklı lokalizasyonlarda görüldü. Fundus ve korpus toplam 10 hasta ile en sık izlenen alanlardı. Dört hastada kardiyada, iki hastada anastomoz hattı komşuluğunda ve birer hastada da incisura angularis ve bulbusta lezyon izlendi. Bu hastalara uygulanan endoskopik tedaviler farklılık göstermekteydi. Klips, tek başına veya kombine olmak üzere en sık başvurulan endoskopik tedavi yöntemiydi. Sadece iki olguda klips dışı endoskopik tedavi yöntemleri kullanılmıştı (Tablo 2).

Ölen hastaların cinsiyetleri incelendiği zaman kadın hastaların \%71,4'ünde (5 hasta) ölüm görülürken erkek hastaların \%18,2'sinde (2 hasta) ölüm olmuştu. Kadın hastalardaki mortalite oranı istatistiksel olarak anlamlıydı $(p=0,04)$.

Mortalite gerçekleşen hastalar ile yaşayan hastalar arasında mortaliteyi öngörebileceği düşünülen bazı parametreler çalışıldı. Bu paramatreler hastaların yaşı, laboratuvar verileri, yatış gün sayısı ve endoskopik tedavi sayısı olarak kabul edildi. Mortalite görülen ve görülmeyen hastalar arasında bakılan parametreler arasında fark yoktu (Tablo 3).

Endoskopik tedaviye rağmen hastaların yedi tanesi eks olmuştu. Bu hastalara yapılan endoskopik tedavilere bakıldığı zaman üç hastada tek başına klips $(\% 42,8)$, iki hastada klips ve beraberinde adrenalin $(\% 28,6)$, iki hastada da adrenalin ve heater probe $(\% 28,6)$ uygulanmıştı

Tablo 2. Dieulafoy yerleşim yeri ve uygulanan endoskopik tedaviler

\begin{tabular}{|c|c|}
\hline Değişken & Sayı \\
\hline \multicolumn{2}{|l|}{ Dieulafoy lokalizasyonu } \\
\hline Fundus & $5(\% 27,8)$ \\
\hline Korpus & $5(\% 27,8)$ \\
\hline Kardiya & $4(\% 22,2)$ \\
\hline İncisura angularis & $1(\% 5,6)$ \\
\hline Bulbus & $1(\% 5,6)$ \\
\hline Anastomoz hattı & $2(\% 11,1)$ \\
\hline \multicolumn{2}{|l|}{ Endoskopik tedavi } \\
\hline Klips & $8(\% 44,4)$ \\
\hline Klips+adrenalin & $6(\% 33,3)$ \\
\hline Heater probe+adrenalin & $2(\% 11,1)$ \\
\hline Klips+adrenalin+heater probe & $1(\% 5,6)$ \\
\hline Klips+Bant & $1(\% 5,6)$ \\
\hline
\end{tabular}


(Tablo 4). Her üç tedavi arasında mortalite açısından istatistiksel bir fark yoktu $(p=0,5)$. Klipsin tek başına uygulandığı sekiz hastanın üç tanesinde $(\% 37,5)$ mortalite görülürken klipsle beraber veya klips olmadan kombine tedavi uygulanan 10 hastadan dört tanesinde (\%40) mortal seyretmişti. Monoterapi ve kombine tedavi arasındaki mortalite oranlarında farklılık görülmedi $(p=0,9)$. Adrenalinle beraber heater yapılan olgular dışlanarak yapılan subgrup analizinde klips uygulanan hastalarla (8 hasta, 3 eks, \%37,8) klipsle beraber diğer yöntemlerin yapıldığı hastalar (8 hasta, 2 eks, \%25) arasında mortalite karşılaştırıldı. İki grup arasında yine mortalite açısından bir fark yoktu $(p=0,6)$. Hastaların takiplerinde 3 hastada tekrar kanama oldu. Bu hastaların hepsinde mortalite izlendi. Tekrar kanama görülen hastaların iki tanesine adrenalinle beraber heater koagülasyon, bir hastaya da klips tedavisi uygulanmıştı.

\section{TARTIŞMA}

Çalışmamız DL'na bağlı oluşan üst gastrointestinal sistem kanamalarında mortalitenin yüksek olduğunu göstermektedir. Fleksibl endoskoplardan önce mortalite oranı $\% 80$ 'lere ulaşırken günümüzde ileri endoskopik tekniklerle bu oran \% 20'lerin altına gerilemiştir (3). Çalışmamızda hastalarımızın yaş ortalamalarının yüksek olması berabe- rinde getirdiği ko-morbid hastalıklarla beraber mortalitenin literatüre göre yüksek olmasının bir nedeni olabilir. Yine kadın hastalarda mortalitenin erkek hastalara göre fazla olması da kadın hastaların ortanca yaşlarının erkek hastalardan daha yüksek olmasıyla açıklanabilir. Literatürle uyumlu olarak DL en sık midede tespit edilmiştir (4). Yaş, hemoglobin, lökosit, platelet, karaciğer enzimleri gibi farklı parametreler mortaliteyi öngörmede kullanışsız bulunmuştur. Çalışmamız klips tedavisine eklenecek adrenalin ve/veya heater koagülasyon gibi yöntemlerle yapılan kombine tedavinin mortaliteyi azaltmada klips monoterapisine kıyasla herhangi bir üstünlüklerinin olmadığını da göstermiştir. Bu bulgu hemoklips tedavisinin Dieulafoy tedavisindeki bilinen etkinliği ile uyumludur. Literatürde tek başına epinefrin enjeksiyonu veya heater koagülasyon uygulanan hastalarda tekrarlayan kanama ve hemostaz başarısızlık oranlarının klips ve bant gibi endoskopik mekanik tedavilere kıyasla fazla olduğu bilinir $(5,6)$. Bu durum DL tedavisinde endoskopik mekanik yöntemleri ön plana çıkarır.

Dieulafoy lezyonlarının tedavi seçenekleri arasında endoskopik tedavi yöntemleri, anjiyografi ve cerrahi yer almaktadır. Bu tedavi seçeneklerinin hangisinin seçileceğine kanamanın yeri, kanamanın şiddeti ve endoskopide lezyonun tanınması gibi farklı değişkenler etki eder. Zaman

Tablo 3. Mortalite gerçekleşen ve gerçekleşmeyen hastalar arasında bağımsız değişkenlerin karşılaş̧ııııması

\begin{tabular}{|l|c|}
\hline Değişkenler & Mortalite Var \\
\hline Yaş & $79(53-88)$ \\
\hline Endoskopi sayısı & $1(1-3)$ \\
\hline Yatış günü & $13(1-26)$ \\
\hline Hemoglobin & $7,2(5,7-11,2)$ \\
\hline Lökosit & $6.500(5.100-10.000)$ \\
\hline Platelet & $116(25-172.000)$ \\
\hline INR & $1,3(1,1-1,75)$ \\
\hline ALT & $19(5-20)$ \\
\hline AST & $30(11-83)$ \\
\hline GGT & $50(21-60)$ \\
\hline ALP & $57(39-75)$ \\
\hline Total protein & $6(5,1-6,1)$ \\
\hline Albümin & $3(1,5-3,4)$ \\
\hline
\end{tabular}

INR: Uluslararası normalleştirilmiş oran, ALT: Alanin aminotransferaz, AST: Aspartat aminotranferaz, GGT: Gama glutamil transpeptidaz, ALP: Alkalen fosfataz

Tablo 4. Endoskopik tedavi metodları arasında mortalite oranlarının karşılaştırılması

\begin{tabular}{|c|c|c|c|c|}
\hline & Klips & Klips+Adrenalin & Adrenalin+Heater & p \\
\hline Mortalite & 3 hasta $(3 / 8)$ & 2 hasta $(2 / 6)$ & 2 hasta $(2 / / 2)$ & 0,5 \\
\hline
\end{tabular}


içerisinde endoskopik tedavi yöntemleri bu lezyonların tedavisinde ilk tercih edilen yöntemler haline gelmiş olup bu yöntemlerin başarı oranı \%75-100 arasında değişir $(7,8)$.

Literatürde DL tedavisinde farklı bir çok endoskopik yöntemin kullanıldığı görülmektedir. Bu yöntemler arasında adrenalin enjeksiyon tedavisi, argon plasma koagülasyon, siyanoakrilat enjeksiyonu, hemoklips ve bant ligasyonu yer almaktadır. Bu yöntemler arasında klips ve bant ligasyonu ilk tercih edilen endoskopik tedavi yöntemleri olarak değerlendirilir (8). Yamaguchi ve arkadaşlarının yaptıkları çalışmada hemoklips \%94 oranında hemostazı sağlamada başarılı olmuştur (9). Parra-Blanco ve arkadaşIarının yaptıkları çalışmada hemoklips uygulanan hastaların prospektif takiplerde sadece bir tanesinde tekrar kanama görülmüştür (10). Hemoklipsin effektivitesi diğer çalışmalarla da gösterilmiştir $(11,12)$. Benzer şekilde bant ligasyonu uygulanılan hastalarda da hemostazın başarılı bir şekilde sağlandığı ve tekrar kanama oranının ise çok düşük olduğu görülmüştür (13). Kombine yöntemlerin (epinefrinle beraber hetaer koagülasyon, epinefrinle beraber hemoklips) de DL tedavisinde etkinlikleri farklı çalışmalarda araştırılmıştır. Bu çalışmalar sıklıkla küçük hasta sayısı içeren çalışmalar olup sonuçları kombine yöntemlerin monoterapiye kıyasla etkinlik bakımından üstünlüklerini gösterememiştir (14).

Sonuç olarak DL morbidite ve mortalitesi fazla olabilen bir gastrointestinal sistem kanama nedenidir. Gastrointestinal sistem kanaması ile gelen ve ilk endoskopisinde etiyolojik bir neden bulunamayan hastalarda DL özellikle akılda tutulmalıdır. Endoskopi DL'de tercih edilen tanısal yöntem olup özellikle aktif kanama esnasında tanısal değeri daha fazladır. Kanamanın lezyonu kapaması veya küçük olan lezyonun gözden kaçırılması ilk endoskopide lezyonun tanınmamasına yol açar ve DL tanısının konulabilmesi için birden çok endoskopik işlem gerekebilir. DL tedavisi için seçkin endoskopik tedavi yöntemi literatür bilgileri ışı̆̆ında hemoklips ve bant ligasyonunu içeren endoskopik mekanik yöntemler olmalıdır.

\section{KAYNAKLAR}

1. Rotondano G. Epidemiology and diagnosis of acute nonvariceal upper gastrointestinal bleeding. Gastroenterol Clin North Am 2014;43:643-63.

2. Marangoni G, Cresswell AB, Faraj W, et al. An uncommon cause of life-threatening gastrointestinal bleeding: 2 synchronous Dieulafoy lesions. J Paediatr Surg 2009;44:441-3.

3. Joarder Al, Faruque MS, Nur-E-Elahi M, et al. Dieulafoy's lesion: an overview. Mymensingh Med J 2014;23:186-94

4. Chaer R, Helton WS. Dieulafoy's disease. Am Coll Surg 2003;196:290-6.

5. Chung IK, Kim EJ, Lee MS et al. Bleeding Dieulafoy's lesions and the choice of endoscopic method: comparing the hemostatic efficacy of mechanical and injection methods. Gastrointest Endosc 2000;52:721-4.

6. Alis $\mathrm{H}$, Oner $\mathrm{OZ}$, Kalayci MU, et al. Is endoscopic band ligation superior to injection therapy for Dieulafoy lesion? Surg Endosc 2009;23:1465-9.

7. Park $\mathrm{CH}$, Joo $\mathrm{YE}$, Kim HS, et al. A prospective, randomized trial of endoscopic band ligation versus endoscopic hemoclip placement for bleeding gastric Dieulafoy's lesions. Endoscopy 2004;36:67781.

8. Valera JM, Pino RQ, Poniachik J, et al. Endoscopic band ligation of bleeding Dieulafoy lesions: the best therapeutic strategy. Endoscopy 2006:38:193-4.

9. Yamaguchi $Y$, Yamato T, Katsumi N, et al. Short-term and longterm benefits of endoscopic hemoclip application for Dieulafoy's lesion in the upper GI tract. Gastrointest Endosc 2003;57:653-6.

10. Parra-Blanco A, Takahashi $H$, Méndez Jerez PV et al. Endoscopic management of Dieulafoy lesions of the stomach: a case study of 26 patients. Endoscopy 1997;29:834-9.

11. Park $\mathrm{CH}$, Sohn $\mathrm{YH}$, Lee WS et al. The usefulness of endoscopic hemoclipping for bleeding Dieulafoy lesions. Endoscopy 2003;35:388-92.

12. Lara LF, Sreenarasimhaiah J, Tang SJ et al. Dieulafoy lesions of the Gl tract: localization and therapeutic outcomes. Dig Dis Sci 2010;55:3436-41.

13. Nikolaidis N, Zezos P, Giouleme $O$, et al. Endoscopic band ligation of Dieulafoy-like lesions in the upper gastrointestinal tract. Endoscopy 2001;33:754-60.

14. Nojkov B, Cappell MS. Gastrointestinal bleeding from Dieulafoy's lesion: Clinical presentation, endoscopicfindings, and endoscopic therapy. World J Gastrointest Endosc 2015;7:295-307. 